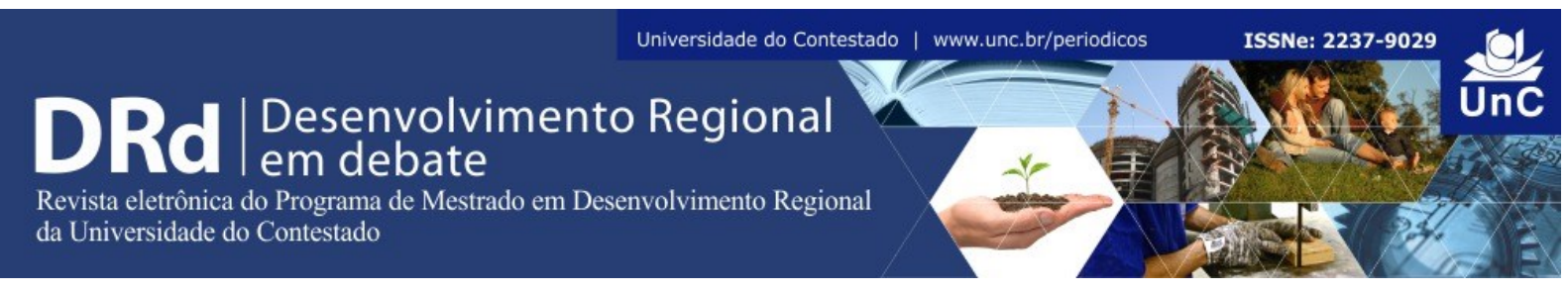

\title{
O PROGRAMA NACIONAL DE SEGURANÇA DO PACIENTE E AS IMPLICAÇÕES NOS SERVIÇOS DE SAÚDE COMO ASPECTO RELEVANTE AO DESENVOLVIMENTO REGIONAL
}

Maria Luiza Milani ${ }^{1}$

Fernanda Vandresen ${ }^{2}$

\begin{abstract}
RESUMO
O presente estudo tem como objetivo refletir sobre o Programa Nacional de Segurança do Paciente e as implicações nos serviços de saúde como aspecto relevante ao desenvolvimento regional. Deste modo, ressalta a necessidade da implementação de ações que contribuam para a melhoria dos serviços e para a efetivação do acesso à saúde ao considerar que receber assistência à saúde é um direito de todos e dever do Estado. O profissional não possui o intuito de causar qualquer dano na assistência prestada, pois tem como objetivo principal o cuidado, porém, mesmo de forma não intencional ainda há ocorrência de eventos adversos relacionados à assistência à saúde. Diante disso, o Programa Nacional de Segurança do Paciente se torna ferramenta indispensável para incentivar o desenvolvimento de medidas preventivas para que os serviços tornem o sistema mais seguro. Na coleta de dados exploraram-se documentos da Secretaria Estadual de Saúde de Santa Catarina, relatórios da Vigilância Sanitária Estadual e estudos realizados acerca da temática, no Planalto Norte Catarinense. Os dados evidenciaram as iniciativas que se concretizaram ou estão em consolidação sob influência de aspectos históricos, políticos e culturais de cada município e a existência ou não de um Núcleo de Segurança do Paciente atuante.
\end{abstract}

Palavras-chave: Desenvolvimento Regional. Saúde. Segurança do Paciente. ${ }^{1}$ Doutora em Serviço Social pela Pontifícia Universidade Católica de São Paulo (2004). Mestre em Educação
pela Universidade Federal de Santa Maria (1999). Graduada em Serviço Social pela Faculdade Espírita do
Curitiba (1992). Docente da Universidade do Contestado. Universidade do Contestado. Canoinhas. Santa
Catarina. Brasil. E-mail: marialuiza@unc.br. ORCID: https://orcid.org/0000-0001-7588-9324
${ }^{2}$ Enfermeira. Mestre em Desenvolvimento Regional pela Universidade do Contestado. Docente da Universidade
do Contestado. Universidade do Contestado. Canoinhas. Santa Catarina. Brasil. E-mail: enf fv@yahoo.com.br.
478

DRd - Desenvolvimento Regional em debate (ISSNe 2237-9029)

v. 9 , p. $478-505,2019$. 


\title{
THE NATIONAL PATIENT SAFETY PROGRAM AND IMPLICATIONS IN HEALTH SERVICES AS A RELEVANT ASPECT TO REGIONAL DEVELOPMENT
}

\begin{abstract}
The present study aims to reflect on the National Patient Safety Program and the implications on health services as a relevant aspect of regional development. Thus, it highlights the need to implement actions that contribute to the improvement of services and to the effective access to health, considering that receiving health care is a right of everyone and the duty of the State. The professional does not intend to cause any damage to the care provided, as it has as main objective the care, however, even in an unintentional way there are still occurrences of adverse events related to health care. In view of this, the National Patient Safety Program becomes an indispensable tool to encourage the development of preventive measures so that the services make the system safer. Data collection was carried out by the State Secretariat of Health of Santa Catarina, reports of the State Sanitary Surveillance, and studies carried out on the subject in the Planalto Norte Catarinense. The data showed the initiatives that have been implemented or are being consolidated under the influence of historical, political and cultural aspects of each municipality, and the existence or not of an active Patient Safety Center.
\end{abstract}

Keywords: Regional Development. Cheers. Patient Safety.

\section{INTRODUÇÃO}

Se tomarmos por base que desenvolvimento se constitui por um caráter polissêmico, se pode considerar multivariada possibilidade de o identificar, definir e descrever, uma vez ele contempla a ideia de mudança, crescimento, superação, melhoria e ampliação. Desenvolvimento se torna um princípio vital presente no mundo e para os seres humanos, ao impulsionarem constantemente seu aprimoramento (BAZZANELLA, 2015).

Se considera, pois, que o desenvolvimento é processo pelo qual se articulam capacidades organizativas, produtivas, distributivas e culturais, pelas quais os seres humanos, perseguem a supressão de suas necessidades, interesses, bem-estar e qualidade de vida. Logo, o desenvolvimento regional é o cenário no qual acontece o desenvolvimento em suas múltiplas dimensões. A concepção de desenvolvimento e em especial ao se voltar ao regional, deve portar o significado de promoção da igualdade e da liberdade (SEN, 2000).

Entende-se igualdade como a universalização do acesso e usufruto dos bens socialmente constituídos, logo entre esses bens se insere a saúde, um dos componentes da qualidade de vida. Tanto qualidade de vida como saúde, são resultantes das formas de organização social, das condições gerais de alimentação, das condições de moradia, do acesso à educação, da relação com o meio ambiente, do emprego e renda, das oportunidades de lazer, da posse de terra e acesso aos serviços de saúde (BRASIL, 1987).

Relacionando esses referenciais, é possível considerar que a saúde de um povo pode ser um dos aspectos fundamentais para o desenvolvimento de uma região. Se a saúde é um bem socialmente necessário à qualidade de vida, o desenvolvimento de uma sociedade pode ser

DRd - Desenvolvimento Regional em debate (ISSNe 2237-9029) 
identificado, mensurado e descrito. Para estes acontecerem destaca-se a operacionalização de políticas públicas as quais devem produzir melhorias nas condições de vida de determinada população.

Isto posto, na operacionalização de políticas públicas há um processo complexo constituído de determinações que representam interesses de atores sociais locais, regionais e internacionais. No âmbito da saúde e da saúde pública, esses interesses buscam responder ao disposto constitucional (Constituição da República Federativa do Brasil, 1988), da integralidade, universalidade e gratuidade, para o que as diretrizes internacionais contribuem com os processos brasileiros no escopo local e regional.

Em um recorte particular da complexidade da política pública de saúde brasileira, que referenda o princípio da integralidade (BRASIL, 1990) por meio de um Sistema Único de Saúde (SUS), o Brasil faz parte das alianças e fóruns internacionais, como é sua participação na Aliança Mundial de Segurança do Paciente (BRASIL, 2015a). Como se destacará adiante neste texto, a discussão de questões da saúde mais ou menos complexas, buscam a melhoria continuada das estruturas, serviços e profissionais no que tange ao compromisso do dever do estado para o direito universal do brasileiro.

Sob esta diretriz da qualidade da saúde pública para a qualidade de vida do povo brasileiro, em $1^{\circ}$ de abril de 2013, o Ministério da Saúde instituiu o Programa Nacional de Segurança do Paciente (PNSP), por meio da Portaria MS/GM n ${ }^{0}$ 529. O programa tem como objetivo fortalecer ações em todos os estabelecimentos de saúde visando a segurança do cuidado ao paciente (BRASIL, 2015a). Desde então, as instituições de saúde devem ter implantado o Núcleo de Segurança do Paciente, para através deste proporcionar discussões e implantar protocolos, bem como, um plano de segurança do paciente institucional.

Retomando os aspectos do tema, é preciso marcar aspectos relativos à saúde pública brasileira, recortando-se as contribuições da Reforma Sanitária para a efetivação do direito à saúde consolidado pela criação do SUS, assegurado na Constituição da República Federativa Brasileira (1988). As bases do SUS foram delineadas na $8^{\text {a }}$ Conferência Nacional da Saúde, em 1986, as quais foram referendadas pela Constituição posteriormente.

Entre as principais bases dessa Conferência Nacional de Saúde se concebe: o dever do Estado e direito do cidadão à saúde; a reformulação do Sistema Nacional de Saúde vigente no período; e, o financiamento do setor. Também foram amplamente discutidos temas específicos, como a hierarquização dos cuidados médicos segundo sua complexidade e especialização e a participação popular nos serviços de saúde.

O Sistema Único de Saúde tornou-se referência para toda a América Latina e instrumentalizou-se pelo artigo 198 da Constituição da República Federativa Brasileira:

Art. 198. As ações e serviços públicos de saúde integram uma rede regionalizada e hierarquizada e constituem um sistema único, organizado de acordo com as seguintes diretrizes: I - Descentralização, com direção única em cada esfera de governo; II Atendimento integral, com prioridade para as atividades preventivas, sem prejuízo dos serviços assistenciais; III - participação da comunidade (BRASIL, 1988).

Conforme previsto pelo SUS, a saúde no Brasil traz uma série de princípios para sua preservação, e deve ser prestada por um sistema regionalizado e hierarquizado. A necessidade de melhoria na assistência prestada pelos profissionais de saúde tem recebido atenção especial,

DRd - Desenvolvimento Regional em debate (ISSNe 2237-9029) 
não só no Brasil, mas em âmbito global. "A Organização Mundial de Saúde (OMS) estima que todos os anos dezenas de milhares de pessoas sofrem danos desnecessários causados por serviços de saúde inseguros" (BRASIL, 2015, p. 07).

Os danos e erros resultantes de atendimento aos pacientes têm sido relatados e estudados cada vez mais e mostram que embora o cuidado humano traga inúmeros benefícios, a ocorrência de erros tem sido mais frequente. Estes erros se tornam um dos principais motivos que direcionam para a necessidade de aprofundar a evolução histórica dos principais acontecimentos e as recomendações inerentes à segurança do paciente até os dias atuais (SILVA, 2012).

Reduzir a ocorrência de eventos adversos pode ser considerado como um desafio a ser superado em relação à segurança do paciente. É sabido que a causa dos erros é multifatorial e principalmente quando os processos assistenciais são complexos e mal planejados, os profissionais e pacientes estão suscetíveis. Na assistência à saúde sempre há possibilidade de riscos e danos ao paciente e esta realidade não pode mais ser ignorada, estudos da OMS apontam que cerca de $10 \%$ dos pacientes internados sofrem eventos adversos (BRASIL, 2015).

A ocorrência desses eventos adversos tem gerando cada vez mais discussões sobre a qualidade do cuidado em serviços de saúde, pois vem preocupando os estudiosos, os profissionais e os gestores de saúde (MENDES et al., 2008).

Destacados os aspectos preliminares do texto, saúde e desenvolvimento, o estudo contempla a escala regional, ou seja, o desenvolvimento regional, pois este se dedica a uma região geográfica, política e a uma regional de saúde. Dito isto, o estudo almeja como objetivo refletir sobre o Programa Nacional de Segurança do Paciente e as implicações nos serviços de saúde como aspecto relevante ao desenvolvimento regional.

O presente estudo é de natureza aplicada tendo uma abordagem quali-quantitativa, com objetivo exploratório e descritivo, de caráter documental. O universo da pesquisa é a região do Planalto Norte Catarinense, formada por 13 municípios: Bela Vista do Toldo, Campo Alegre, Canoinhas, Irineópolis, Itaiópolis, Mafra, Major Vieira, Monte Castelo, Papanduva, Três Barras, Porto União, Rio Negrinho e São Bento do Sul.

A coleta de dados secundários foi realizada de setembro de 2018 a janeiro de 2019, mediante consulta em documentos da Secretaria Estadual de Saúde de Santa Catarina, site da Agência Nacional de Vigilância Sanitária (ANVISA), que disponibiliza indicadores de saúde a nível nacional, estadual e municipal, e publicações de duas pesquisas regionais voltadas ao Programa Nacional de Segurança do Paciente que retratam a implantação nos hospitais públicos e atividades realizadas a partir de 2013. Na coleta de dados exploraram-se dados secundários visando uma exploração comparativa de registros.

Apresenta-se aportes das iniciativas brasileiras da segurança do cuidado ao paciente, complementa-se essas iniciativas no Estado de Santa Catarina e em seguida algumas discussões sobre a provável relação entre a saúde e o desenvolvimento regional, por fim, a experiência da segurança do cuidado ao paciente na região denominada Planalto Norte Catarinense. 


\section{INICIATIVAS BRASILEIRAS DA SEGURANÇA DO CUIDADO AO PACIENTE}

A busca por melhoria na qualidade da assistência prestada pelos profissionais de saúde tem recebido atenção especial, não só no Brasil como no âmbito global.

Hipócrates (460 a 370 a.C.) cunhou o postulado Primum non nocere, que significa primeiro não cause o dano. O pai da Medicina tinha a noção, desde essa época, que o cuidado poderia evitar algum tipo de dano (LOEFLER, 2002). Também Florence Nightingale, um dos marcos da enfermagem moderna, sustentava que o primeiro dever de um hospital deveria ser o de não causar mal ao paciente. Em seu trabalho na Guerra da Criméia (1853 a 1856), observou que as condições de atendimento aos soldados eram muito precárias, com isso, juntamente com outras voluntárias, priorizou a segurança dos feridos para proporcionar qualidade nos cuidados prestados (NIGHTINGALE, 1863).

O relatório publicado por James Reason, psicólogo britânico, em 1999 nos Estados Unidos intitulado "Errar é humano: construindo um Sistema de Saúde mais Seguro", foi um marco acerca do tema, pois relatou a frequência de erros na assistência à saúde nos hospitais, e que as falhas devem ser abordadas de forma holística, pois resultam de falhas no sistema de saúde e não com foco nos profissionais envolvidos no evento (WACHTER, 2010). Ganhou notoriedade global, pois ao realizar revisões de prontuários apontou que cerca de 100.000 pessoas morrem por ano, vítimas de eventos adversos. Essa publicação contribuiu para mudanças nas práticas de saúde (BRASIL, 2013).

Segundo Corbellini et al (2011, p. 242) "[...] quando uma pessoa procura um serviço de saúde, pressupõe-se que o profissional esteja habilitado, capacitado e qualificado para atendêla com segurança". Isso é o que se espera das instituições de saúde, que tenham excelência no cuidado e ofereçam qualidade e segurança no atendimento.

Para Kalsing (2012) o ser humano está sujeito a realizar tarefas que apresentem não conformidades, que são denominadas de evento adverso. Os erros e danos causados aos pacientes durante o atendimento médico-hospitalar têm sido descritos e estudados cada vez mais, mostrando em evidências que, embora o cuidado humano traga inúmeros benefícios, os erros estão sendo mais frequentes aos pacientes. Este é um dos motivos que direcionam para compreender o andamento histórico dos principais acontecimentos e modificações inerentes à segurança do paciente (SILVA, 2012).

Considerando que boa parte dos cuidados em saúde é realizada fora dos hospitais, estudos apontam que na atenção primária à saúde os incidentes acontecem em proporção de 5 a 80 vezes a cada 100.000 atendimentos (SANDARS; ESMAIL, 2003), sendo a administração de medicamentos em domicílio contribuinte com as intercorrências, e 50\% das hospitalizações por causas agudas potencialmente evitáveis (LEENDERTSE et al., 2008). Assim, entende-se neste estudo, que a segurança do paciente é relevante em todos os
níveis de atenção à saúde, uma vez que o cuidado não se restringe somente à
prescrição e administração de medicamentos de forma correta e a prevenção de
processos infecciosos durante a realização de procedimentos, mas envolve também a
prevenção dos erros e eventos adversos, bem como, a análise de suas ocorrências, a
gestão dos recursos humanos, a efetiva liderança organizacional e o fortalecimento da
cultura de segurança (PAESE, 2010, p. 32). 
A OMS publica periodicamente campanhas de sensibilização aos países que aderiram a Aliança Mundial em Prol da Segurança do Paciente para prevenção de evento adverso no cuidado à saúde. Desde então, nomeou de desafios globais, aspectos considerados essenciais para promover a segurança na assistência. Cada desafio propõe estratégias preventivas acerca da temática, sendo em 2004 "Cuidado Limpo é Cuidado Seguro", visando garantir a melhoria da higienização das mãos dos profissionais que atuam no cuidado, em 2008 "Cirurgias Seguras Salvam Vidas", visando melhorar a segurança do tratamento cirúrgico em todos os contextos de cuidados de saúde e em 2011 "Enfrentar a Resistência Antimicrobiana" como uma prioridade e o foco do Dia Mundial da Saúde (BRASIL, 2015a).

$\mathrm{O}$ avanço nas pesquisas de cuidado à saúde contribui para a melhoria do cuidado prestado. Mesmo com o progresso no sistema de saúde, o paciente ainda está exposto a diversos riscos quando submetido a cuidados. O paciente está sob risco quando recebe os cuidados relacionados à sua saúde e a segurança do paciente tem sido reconhecida como um componente extremamente importante da qualidade em saúde (BRASIL, 2014a).

Para Padilha (2006) os eventos adversos são ocorrências indesejáveis e preveníveis, mas que ocasionam danos e comprometem a segurança do paciente. Esse autor ainda, considera esse fato quando se refere a alguém que está sob os cuidados de profissionais da área da saúde. A Teoria do Queijo Suíço explica que os eventos adversos ocorrem por uma junção de eventos e barreiras que não foram adotadas, e isso faz com que a associação dos fatores predisponentes resulte no evento adverso. Por isso, é necessário analisar e conhecer os aspectos relacionados ao fato, criando assim diferentes possibilidades de gerenciar os riscos, como se houvesse a possibilidade de criar barreiras que pudessem de certa forma obstruir esses buracos, impedindo o realinhamento, com o que esses erros latentes não estariam mais alinhados e não atingiriam o paciente (WACHTER, 2010).

Em concordância com a Teoria do Queijo Suíço, a OMS acrescenta que "[...] erros têm diversas causas, que podem estar ligadas ao indivíduo, às tarefas que devem ser executadas, à conjuntura ou à própria organização" (WHO, 2016, p.100). Deste modo, a redução dos eventos adversos ainda é um desafio a ser superado em relação à segurança do paciente. A causa dos erros é multifatorial e os profissionais estão suscetíveis principalmente quando os processos são complexos e mal planejados. Uma assistência quando prestada por seres humanos sempre há possibilidade de riscos e danos ao paciente e esta realidade não pode mais ser ignorada (BRASIL, 2015a).

Silva (2003) cita alguns sinônimos de eventos adversos: ocorrências de eventos iatrogênicos; erros de enfermagem; ocorrências, reações; complicações iatrogênicas; iatrogenias; doença iatrogênica e falhas. $\mathrm{O}$ autor considera que todos os termos supracitados não são intencionais.

O crescente número de ocorrência desses eventos adversos vem preocupando estudiosos, profissionais e gestores de saúde, gerando cada vez mais discussões sobre a qualidade do cuidado em serviços de saúde (MENDES et al., 2008). A OMS define erro como não intencional, embora possa ocasionar um evento adverso. Os profissionais deixam evidente que o fato não é esperado no trabalho da enfermagem, principalmente por considerarem ser prejudicial ao paciente (KALSING, 2012).

DRd - Desenvolvimento Regional em debate (ISSNe 2237-9029) 
As iniciativas relacionadas à segurança do cuidado ao paciente no Brasil surgiram a partir de 1990, visando adotar programas de garantia da qualidade, tanto em instituições privadas quanto públicas, tendo como principais propósitos uma assistência isenta de danos e a satisfação do cliente (DONABEDIAN, 1994). As primeiras pesquisas no Brasil foram influenciadas pelo panorama global no início da década de 2000 Estas “[...] demonstraram que os processos hospitalares não se encontravam organizados e adequados para garantir uma assistência segura e associado a essa complexidade, a limitação humana que, inevitavelmente, tem como efeito os erros" (BUENO; FASSARELLA, 2012, p. 5).

Em 2001 outra iniciativa brasileira na área de segurança da assistência foi a criação de um projeto chamado de "Hospitais Sentinela". Esse projeto objetivava ampliar a vigilância de produtos utilizados na assistência à saúde. Em 2002 a iniciativa passou a ser chamada de Rede Sentinela, pois além do acompanhamento das tecnologias e produtos anteriormente monitorados, contemplou a busca ativa de eventos adversos e a notificação destes (BRASIL, 2003c).

A Rede Brasileira de Enfermagem e Segurança do Paciente (REBRAENSP), surgiu pela primeira vez em São Paulo em maio de 2007, com apoio da OPAS “[...] como meio de potencializar o conhecimento e esforços da enfermagem comprometida com o desenvolvimento permanente desta área no Brasil” (REBRAENSP, 2015).

Também em 2007, na XXII Reunião de Ministros da Saúde do Mercado Comum do Cone Sul (MERCOSUL) o Brasil, juntamente com Argentina, Paraguai, Uruguai, Bolívia, Chile e Equador assumiram o compromisso não somente para reduzir os riscos a que são submetidos os pacientes que recebem assistência nos serviços de saúde, mas se comprometeram a garantir o direito à saúde. $\mathrm{Na}$ reunião os países do Mercosul apoiaram o primeiro desafio global da Aliança Mundial para a Segurança do Paciente: Cuidado Limpo é Cuidado Seguro (BRASIL, 2013).

Nessa ótica, o Brasil é um dos países que compõem a Aliança Mundial para a Segurança do Paciente. Nesse contexto, o Ministério da Saúde instituiu o Programa Nacional de Segurança do Paciente, por meio da Portaria MS/GM n ${ }^{\circ} 529$, de $1^{\circ}$ de abril de 2013, com o objetivo geral de contribuir para a qualificação do cuidado em saúde em todos os estabelecimentos de saúde do território nacional (BRASIL, 2011).

De acordo com a definição da Organização Mundial de Saúde, Segurança do Paciente significa reduzir a um mínimo aceitável, o risco de dano desnecessário associado ao cuidado de saúde. Sendo assim, em consonância com o panorama mundial, a Agência Nacional de Vigilância Sanitária (ANVISA) e o Ministério da Saúde programam ações e estratégias visando a Segurança do Paciente (SP) por intervenção de legislações e projetos (BRASIL, 2014a).

Segundo a Anvisa (BRASIL, 2011, p. 01) “[...] errar é humano, mas é possível construir um sistema mais seguro". Partindo deste princípio, o tema deve ser abordado nos serviços de saúde objetivando a sensibilização dos profissionais para uma prática mais segura e consciente.

Sherwood e Zomorodi (2014) dizem que além dos custos financeiros, tais erros podem causar um impacto emocional nos pacientes e familiares, como também a perda da confiança nos profissionais e na instituição. 
Está previsto na Portaria $n^{\circ} 529$ de 01 de abril de 2013, e na RDC no 36 de 26 de julho de 2013 que a implantação do Núcleo de Segurança do Paciente (NSP) em todos os serviços de assistência à saúde é obrigatória para "[...] promover e apoiar a implementação de iniciativas voltadas à segurança do paciente" (BRASIL, 2014a, p. 22). Nesta direção cada hospital deve implantar um núcleo específico para sua realidade e as unidades de Atenção Básica podem possuir um único a nível local (BRASIL, 2014a).

O Programa Nacional de Segurança do Paciente (PNSP) traz a implantação de seis protocolos básicos de segurança do paciente, com objetivo principal de promover a segurança no atendimento com a criação de barreiras preventivas e mudanças nos processos de trabalho em todos os serviços de saúde, sendo público ou privados do território nacional. Esses protocolos foram elaborados por profissionais da área e publicados pela Agência Nacional de Vigilância Sanitária (ANVISA), o Ministério da Saúde (MS) e Fiocruz. Estes protocolos deverão ser adaptados à realidade de cada instituição de saúde, e monitorados após implantação (BRASIL, 2014a).

Os protocolos tratam das seis metas internacionais de segurança do paciente: identificar corretamente o paciente; melhorar a comunicação entre profissionais de saúde; melhorar a segurança na prescrição, no uso e na administração de medicamentos; assegurar a cirurgia em local de intervenção, procedimento e paciente corretos; higienizar as mãos para evitar infecções; reduzir o risco de quedas e úlceras por pressão (BRASIL, 2014a).

Além da implantação dos Núcleos de Segurança do Paciente (NSP) e dos protocolos supracitados, os serviços de saúde devem realizar as notificações dos eventos adversos (EA), tanto para a instituição de saúde quanto para a ANVISA por meio do Sistema de Notificação em Vigilância Sanitária (NOTIVISA). A ausência de um sistema de monitoramento e avaliação é considerado um ponto crítico para a segurança do paciente (BRASIL, 2014a).

Um dos objetivos das notificações é para que os serviços de saúde possam conhecer os fatores contribuintes "[...] que são circunstâncias, ações ou influências que desempenham um papel na origem ou no desenvolvimento de um incidente ou no aumento do risco de incidente" (BRASIL, 2013, p. 21). As investigações devem considerar as seguintes possibilidades de fatores: humanos, que envolvem o(s) profissional (is) de saúde; sistêmico, pode envolver o ambiente de saúde; relacionados ao paciente; e fatores externos (BRASIL, 2013).

Segundo a OMS, serviços de saúde que têm implantado a notificação e investigação de EA “[...] são mais capazes de aprender com os erros porque os funcionários sentem-se à vontade para relatar problemas reais ou potenciais sem medo de serem ridicularizados ou repreendidos" (WHO, 2016, p. 156). A adesão a essa estratégia, permite que as lideranças identifiquem ou eliminem os fatores relacionados aos EA.

A Nota Técnica 01/2015 que fornece orientações gerais para a notificação de eventos adversos relacionados à assistência à saúde, além de instruções para os serviços de saúde e profissionais de saúde, fornece detalhes do passo a passo para o cidadão ou familiar realizar a notificação dos eventos adversos (BRASIL, 2015b).

Deste modo, e sob tal complexidade, Foucault reflete sobre a vigilância e controle, e traz a noção de panoptismo, que vai além do modelo arquitetônico que este representa. $\mathrm{O}$ panóptico "[...] deve ser compreendido como um modelo generalizável de funcionamento; uma maneira de definir as relações de poder com a vida cotidiana dos homens" (FOUCAULT, 1996,

DRd - Desenvolvimento Regional em debate (ISSNe 2237-9029) 
p. 185). Neste modelo, a vigilância se torna constante, a tal ponto que, cada pessoa passa a se vigiar, indiferente de outra pessoa o fazer. O autor considera este comportamento como o nível mais alto da vigilância, pois a pessoa não admite cometer infrações, ou quebrar regras, pois:

[...] seu funcionamento é de uma rede de relações de alto a baixo, mas também até um certo ponto de baixo para cima e lateralmente; essa rede "sustenta" o conjunto, e o perpassa de efeitos de poder que se apoiam uns sobre os outros: fiscais perpetuamente fiscalizados (FOUCAULT, 1996, p. 158).

Salienta-se que, o Brasil é um dos países que considera a notificação de eventos adversos como critério obrigatório, assim a vigilância se dá pela conscientização, porém é uma forma de tentar controlar as pessoas envolvidas, o que aos poucos permite ampliar as relações de poder. "E isto de várias maneiras: porque pode reduzir o número dos que o exercem, ao mesmo tempo em que multiplica o número daqueles sobre os quais é exercido" (FOUCAULT, 1996, p. 186).

O panóptico é aplicável quando o objetivo é manter sob vigilância um número considerável de pessoas, podendo este ser considerado em qualquer estabelecimento quando a intenção é determinar um comportamento ou estabelecer regras para a realização de tarefas (FOUCAULT, 1996). Regras estas, que são estabelecidas conforme o Documento de Referência para o PNSP (BRASIL, 2014a): há quatro eixos em sua composição: "O estímulo a uma prática assistencial segura; o envolvimento do cidadão na sua segurança; a inclusão do tema no ensino; e o incremento de pesquisa sobre o tema" (BRASIL, 2014a, p. 16). A cultura de segurança do paciente é elemento presente em todos esses eixos. "A portaria destacou a necessidade de incluir o tema segurança do paciente no ensino técnico e de graduação, na pósgraduação na área da Saúde e na educação permanente dos profissionais da Saúde" (BRASIL, 2014a, p. 27).

Quando o evento adverso é notificado, posteriormente é realizada a investigação. Uma das ferramentas sugeridas é a análise de causa-raiz, que traz detalhes do ocorrido, com uma investigação minuciosa e extensa, procurando identificar as causas (raízes). Após, os possíveis fatores contribuintes são listados, e estratégias devem ser adotadas para que eventos similares sejam prevenidos (BRASIL, 2015a). Por isso a PNEPS se torna uma ferramenta indispensável na temática.

\section{A APLICAÇÃO DA POLÍTICA NACIONAL DE EDUCAÇÃO PERMANENTE EM SAÚDE EM SANTA CATARINENSE}

O interesse pela educação permanente na abrangência das Políticas Públicas teve destaque em 2003, quando o Conselho Nacional de Saúde (CNS), por meio da Resolução $n^{\circ}$ 335, de 27 de novembro de 2003 aprovou a "Política Nacional de Formação e Desenvolvimento para o SUS: Caminhos para a Educação Permanente em Saúde" juntamente com os "Polos ou Rodas de Educação Permanente em Saúde" como instâncias de gestão da Educação Permanente no âmbito dos profissionais de saúde (BRASIL, 2003b).

Considerando imprescindível a educação dos trabalhadores para a reflexão sobre sua prática, a Política Nacional de Educação Permanente em Saúde (PNEPS) foi instituída pelo 
Ministério da Saúde em 13 de fevereiro de 2004 pela Portaria 198/2004, tendo como proposta estratégica a transformação das práticas de saúde, visando à organização dos serviços, mediante a articulação entre as esferas de gestão, as instituições formadoras, o sistema de saúde e representantes sociais (BRASIL, 2004b).

Em âmbito nacional, inicialmente os chamados "Polos de Educação Permanente" (PEPS), foram criados objetivando a gestão da política, atuando como um dispositivo do SUS para promover mudanças. Estes polos contribuíram de forma significativa para a disseminação da proposta nas diferentes regiões do Brasil, nos espaços locais, microrregionais regionais, estaduais e interestaduais (BRASIL, 2004b). Em 2006, por meio da Portaria 399/2006, foi instituído o Pacto pela Saúde, que apresentou mudanças na gestão da Educação Permanente em Saúde (EPS), e em 2007 com a nova Portaria MS 1.996/07 a mesma foi reestruturada (BRASIL, 2007).

Após essa nova reestruturação os Polos de Educação Permanente foram substituídos pelas Comissões de Integração Ensino-Serviço (CIES):

As Comissões Permanentes de Integração Ensino-Serviço (CIES) são instâncias intersetoriais e interinstitucionais permanentes que participam da formulação, condução e desenvolvimento da Política de Educação Permanente em Saúde, previstas no art.14 da lei 8080/1990 (BRASIL, 2007).

A portaria MS 1.996/07 indica a condução da PNEPS a nível regional, que se dá a partir das Comissões Intergestores Regionais (CIR) juntamente com as CIES. A composição da CIES deverá ser:

I - gestores estaduais e municipais de educação e/ou de seus representantes; II trabalhadores do SUS e/ou de suas entidades representativas; III - instituições de ensino com cursos na área da saúde, por meio de seus distintos segmentos; e IV - movimentos sociais ligados à gestão das políticas públicas de saúde e do controle social no SUS (BRASIL, 2007).

Essa composição foi chamada por Ceccim e Feuerwerker (2004) de o quadrilátero:

Formação se constitui de elementos que interagem e se articulam na produção de novos saberes e práticas. Dentre eles, a formação se apresenta como produtora de subjetividade, de habilidades técnicas e de pensamento para o adequado conhecimento do SUS; as práticas de atenção à saúde como construtoras de novas práticas de saúde, tendo em vista os desafios da integralidade, da humanização e da inclusão dos usuários no planejamento terapêutico; a gestão no desafio da busca de assegurar redes de atenção às necessidades em saúde da população e considerar a satisfação dos usuários; e o controle social com a presença dos movimentos sociais no apoio às lutas pela saúde e à construção do atendimento às necessidades sociais (CECCIM; FEUERWERKER, 2004, p. 43).

O formato de quadrilátero da formação para a área da saúde une: ensino, gestão setorial, práticas de atenção e o controle social. Nessa proposta, os atores se mantém próximos e não em posição de verticalidade, e a mudança ocorrerá desde que todos estejam centralmente comprometidos (CECCIM; FEUERWERKER, 2004).

Segundo o Ministério da Saúde (BRASIL, 2009), a responsabilidade do planejamento das ações bem como a execução das mesmas é dividida nas esferas federais, estaduais e municipais. Cabe a esfera Federal o repasse dos recursos financeiros para os Fundos Estaduais 
e Municipais, com o custeio das diferentes estratégias de acordo com as necessidades identificadas em cada realidade. Assim, deve haver a elaboração do Plano Estadual e Plano de Ação Regional de Educação Permanente em Saúde (PAREPS), para nortear as ações e intervenções na área de educação na saúde.

Para a elaboração do Plano de Ação Regional de Educação Permanente em Saúde, os seguintes aspectos devem ser considerados: caracterização da região de saúde, identificação dos problemas de saúde, caracterização das necessidades de formação em saúde, atores envolvidos, relação entre problemas e as necessidades de educação permanente em saúde, produtos e resultados esperados, processo de avaliação do plano, recursos envolvidos para a execução do plano (BRASIL, 2009).

O Colegiado de Gestão Regional faz a condução da PNEPS com participação das Comissões Permanentes de Integração Ensino-Serviço (CIES). As CIES participam no desenvolvimento, condução e aplicação da Política Nacional reestruturada (BRASIL, 2007). Com essas definições, a EPS torna-se uma estratégia essencial para a dinâmica dos serviços de saúde, com foco no cenário do processo de trabalho coletivo, oportunizando práticas reflexivas, visando à ética e humanização. Seu planejamento consiste em atender às necessidades da equipe de saúde e pacientes, valorizando os diferentes saberes com maior resolutividade e integralidade nas ações. Com essas estratégias de formação, as práticas de saúde são transformadas com base nas necessidades reais, não apenas visando a qualificação do serviço, mas sim tornando o profissional mais seguro de si (FORTUNA et al., 2013).

Lemos (2010) faz uma reflexão sobre a reestruturação do trabalho na lógica da PNEPS, que ao trazer a proposta de novos modelos assistenciais e de aprendizagem significativa, uma política pública estimula a gestão dos processos de trabalho e potencializa as relações nas práticas de saúde.

Para Paulo Freire (1980, p. 66) “[...] a educação é comunicação, é diálogo, na medida em que não é transferência de saber, mas um encontro de sujeitos interlocutores que buscam a significação dos significados”. A educação permanente é uma estratégia para a construção de novas práticas em saúde. Mesmo com a Política Nacional de Educação Permanente, é necessário que haja conscientização dos profissionais quanto a sua relevância e direcionalidade, para possibilitar a transformação das práticas em saúde.

Henckemaier (2016) ao considerar o quotidiano familiar diante da hospitalização, aponta a necessidade do preparo dos profissionais de saúde para a interação e comunicação no momento vivenciado, sendo que estes aspectos podem contribuir positivamente para o cuidado seguro. Já Lima et al. (2016) reconhecem a importância da PNEPS e que a mesma sensibiliza os atores envolvidos, porém fazem uma análise crítica sobre as dificuldades na sua implementação, conforme quadro abaixo: 
O programa nacional de segurança do paciente e as implicações nos serviços de saúde como aspecto relevante ao desenvolvimento regional

Quadro 1 - Potencialidades e fragilidades da PNEPS

\begin{tabular}{|c|c|c|}
\hline Estratégias da PNEPS & Potencialidades & Fragilidades \\
\hline $\begin{array}{l}\text { Desenvolvimento } \\
\text { Profissional }\end{array}$ & $\begin{array}{l}\text { Estratégia utilizada para enfrentar os } \\
\text { problemas de desenvolvimento dos } \\
\text { profissionais de saúde, por meio de } \\
\text { capacitação, ações intencionais e } \\
\text { planejadas que têm como missão } \\
\text { fortalecer conhecimentos, habilidades, } \\
\text { atitudes e práticas } \\
\text { Educação permanente dos trabalhadores } \\
\text { em saúde }\end{array}$ & $\begin{array}{l}\text { A simplificação da capacitação, } \\
\text { influenciada por condições } \\
\text { institucionais, políticas ideológicas e } \\
\text { culturais, que determinam o espaço } \\
\text { dentro do qual a capacitação pode ou } \\
\text { não operar seus limites e } \\
\text { possibilidades } \\
\text { No campo da formação permanente } \\
\text { dos profissionais da saúde, as } \\
\text { mudanças de concepções não } \\
\text { conseguiram superar o enfoque } \\
\text { centrado na transmissão de } \\
\text { conhecimentos de maneira } \\
\text { mecanizada e bancária. Sua } \\
\text { manutenção pode ser explicada pela } \\
\text { persistência do modelo escolar nas } \\
\text { formas de pensar a educação por uma } \\
\text { visão simplificada das pessoas e da } \\
\text { prática no campo das organizações }\end{array}$ \\
\hline $\begin{array}{l}\text { Capacidade Resolutiva } \\
\text { dos Serviços de Saúde }\end{array}$ & $\begin{array}{l}\text { Estratégia para melhorar os níveis de } \\
\text { atenção e funções, bem como, contribuir } \\
\text { para o desenvolvimento de novas } \\
\text { competências práticas (gerência } \\
\text { descentralizada, auto-gestão, gestão de } \\
\text { qualidade) }\end{array}$ & $\begin{array}{l}\text { Nem toda ação é resolutiva. Embora } \\
\text { toda ação de capacitação vise à } \\
\text { melhoria do desempenho dos serviços } \\
\text { de saúde, nem todas representam } \\
\text { parte substantiva de uma estratégia de } \\
\text { mudança institucional. }\end{array}$ \\
\hline $\begin{array}{l}\text { Monitoramento e } \\
\text { Avaliação }\end{array}$ & $\begin{array}{l}\text { A avaliação acompanha cada fase do } \\
\text { desempenho pedagógico, } \\
\text { monitoramento do processo (implica na } \\
\text { identificação dos problemas, das } \\
\text { características, dos obstáculos e os } \\
\text { recursos disponíveis), a análise dos } \\
\text { resultados e as formulações de um juízo } \\
\text { de valor acerca do alcance dos } \\
\text { profissionais formulados. }\end{array}$ & $\begin{array}{l}\text { Somente a partir das discussões } \\
\text { coletivas sobre a aplicação da política, } \\
\text { é que será possível reconhecer as boas } \\
\text { práticas e identificar os impactos das } \\
\text { mesmas sobre os indicadores de } \\
\text { saúde. }\end{array}$ \\
\hline
\end{tabular}

Fonte: Lima et al. (2016, p. 1412-1413).

Merhy (2005) reflete sobre a visão dos gestores referente à ineficácia das ações de saúde. Estes a relacionam com falta de competência da equipe, também faz uma crítica aos métodos tradicionais de ensino aos profissionais de saúde, que contemplam cursos exaustivos que consomem recursos e não repercutem em mudanças práticas à realidade vivenciada.

Vários estudos apontam para os atos inseguros, e os relacionam ao fator humano em decorrência de fatos como: esquecimento, negligência, falta de atenção, motivação, e outras características pessoais, tais como, a personalidade, idade, humor, experiência profissional e o conhecimento científico. Esses fatores devem ser identificados precocemente, visando evitar a ocorrência de erros e favorecer a segurança na assistência (TONDO, 2015). A segurança do paciente por se tratar de um aspecto que reflete diretamente na qualidade do cuidado prestado deveria ser considerada como pré-requisito, pois as instituições desenvolvem atividades 
assistenciais que são complexas, e isso exige uma atualização constante dos conhecimentos e procedimentos técnicos (TONDO, 2015).

A proposta do Ministério da Saúde é que a problematização faça parte do contexto dos trabalhadores, para um aprendizado significativo e define que: "Problematizar significa refletir sobre determinadas situações, questionando fatos, fenômenos, ideias, compreendendo os processos e propondo soluções" (BRASIL, 2005, p. 8). Assim, esse aprendizado pode se transformar em ações concretas de melhoria do cuidado.

Em 28 de novembro de 2017, por meio da Portaria MS n ${ }^{\circ} 3.194$, foi instituído o Programa para o Fortalecimento das Práticas de Educação Permanente em Saúde no SUS (PRO EPS-SUS). O PRO EPS-SUS tem como principal objetivo "[...] estimular, acompanhar e fortalecer a qualificação profissional dos trabalhadores da área da saúde para a transformação das práticas" (BRASIL, 2018a, p. 10). Para que a PNEPS seja mesmo implementada, o desafio da pedagogia da implicação está em inseri-la no cotidiano dos serviços de saúde, para estar articulado no novo agir, gerando transformações na prática da atenção à saúde (MERHY, 2005).

Com essas definições, a EPS torna-se uma estratégia essencial para a dinâmica dos serviços de saúde, com foco no cenário do processo de trabalho coletivo, oportunizando práticas reflexivas, visando à ética e humanização. Seu planejamento consiste em atender às necessidades da equipe de saúde e usuários, valorizando os diferentes saberes com maior resolutividade e integralidade nas ações. Com essas estratégias de formação, as práticas de saúde são transformadas com base nas necessidades reais, não apenas visando a qualificação do serviço, mas sim tornando o profissional mais seguro de si (FORTUNA et al., 2013).

No Estado de Santa Catarina, a PNEPS inicialmente foi conduzida pela denominada Divisão de Educação e Promoção da Saúde da Secretaria de Estado da Saúde. Esta mediou junto aos representantes do Ministério da Saúde, encontros coletivos entre os atores sociais envolvidos no processo. Como resultado desses encontros, inicialmente, ficaram definidos os polos locorregionais de EPS pela Resolução CES/SC n ${ }^{\circ}$ 009/2003. Por meio desta resolução doze (12), polos foram estabelecidos, contemplando uma cobertura de $100 \%$ dos municípios do estado; nesta publicação também foi instituído o Colegiado Transitório de EP para o SUS (MANCIA; CABRAL; KOERICH, 2004).

Em 2004, o colegiado transitório de EP determinou a criação de fórum, constituído pelos seguintes atores: representantes de cada polo; representantes da Secretaria de Estado da Saúde (SES), Conselho Estadual de Saúde (CES), Conselho Estadual de Educação e Conselho de Secretários Municipais de Saúde (COSEMS). Este Fórum foi criado com os seguintes objetivos:

Articular os Polos de EP; fomentar a discussão docente assistencial na rede do SUS; articular pesquisas para avaliação do processo de EP; disseminar propostas de educação permanente recomendando experiências exitosas; acompanhar e avaliar a implantação e implementação das políticas de EP no Estado; promover a discussão conceitual sobre a EP no SUS (MANCIA; CABRAL; KOERICH, 2004, p. 609).

Em 2004, também houve uma reestruturação da divisão e a mesma foi substituída pela Divisão de Educação Permanente (DEP), pela portaria nº198/2004, sendo esta responsável até o momento pela articulação da política no Estado de Santa Catarina (MENDONÇA, et al. 2010). Em seguida foi instituída uma comissão de avaliação das atividades dos Polos

DRd - Desenvolvimento Regional em debate (ISSNe 2237-9029) 
locorregionais, para que os mesmos pudessem tomar conhecimento da PNEPS bem como do repasse de recursos (SANTA CATARINA, 2017).

Cabe ressaltar a necessidade dos municípios que compõe a região de fortalecer a Política de Educação Permanente em Saúde a qual permeia as demais políticas: atenção básica e o PMAQ- Programa de Melhoria de Acesso e da Qualidade, Redes de atenção à saúde, educação popular, controle social, dente outras as quais sinalizam a EPS como estratégia de implementação. O grupo de trabalho ainda identificou a importância da criação e fortalecimento dos Núcleos Municipais de Educação Permanente em saúde e Humanização - NMEPSH, tendo em vista que os municípios possuem recursos do co-financiamento da Atenção Básica, os quais prioritariamente devem ser utilizados para educação permanente em saúde e enfrentam dificuldades na gestão e efetiva aplicação deste recurso (SANTA CATARINA, 2017).

Nesta direção, a Diretoria de Educação Permanente em Saúde (DEPS) coordena a Política de Educação Permanente no Estado de Santa Catarina (PEPESC), juntamente com um Fórum Estadual das Comissões de Integração Ensino/Serviço, “[...] configurado como um espaço de troca de experiências e decisões relativas às ações de Educação Permanente em Saúde entre as 15 CIES em nível estadual” (SANTA CATARINA, 2009, p. 13).

O território catarinense é dividido em 09 Macrorregiões de Saúde, conforme aponta o Plano Diretor de Regionalização - PDR/2008. Essa distribuição visa à organização, o planejamento e a execução de ações e serviços de saúde (SANTA CATARINA, 2008). A Figura 1 demonstra as 9 divisões.

Figura 1 - Configuração das Macrorregiões de Saúde de Santa Catarina

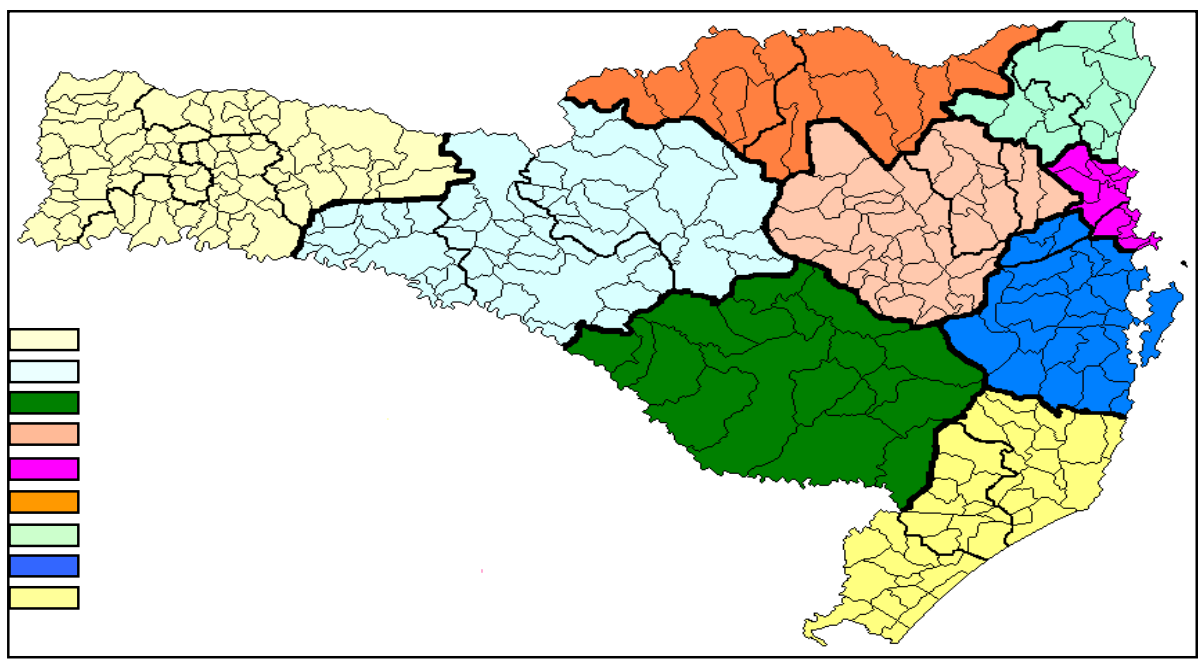

Legenda: Pela ordem das cores, Extremo Oeste, Meio Oeste, Planalto Serrano, Vale do Itajaí, Foz do Rio Itajaí, Planalto Norte, Nordeste, Grande Florianópolis e Sul.

Fonte: PDR/2008 (SANTA CATARINA, 2008).

Com a atuação conjunta da DEPS e os polos regionais atuantes, iniciam-se as discussões periódicas, baseadas em indicadores e necessidades locorregionais. Cada um desses doze (12) polos irá elaborar em conjunto o Plano Estadual de Educação Permanente em Saúde (PEEPS), e também a nível regional a elaboração do Plano Regional para Educação Permanente em Saúde (PAREPS) juntamente com a CIES e CIR (SANTA CATARINA, 2008). 


\section{DEBATE ENTRE SAÚDE E DESENVOLVIMENTO REGIONAL}

As definições de saúde não se restringem à medicina, se dão a partir de uma ampla gama de saberes, pois alcançam outras áreas do conhecimento como a filosofia, a sociologia, a antropologia, o direito, enfim, toda a equipe multidisciplinar. Conforme definição na Carta de Ottawa, várias condições são fundamentais para a saúde: paz, habitação, educação, alimentação, renda, ecossistema estável, recursos sustentáveis, justiça social e equidade (OTTAWA, 1986).

A Carta de Ottawa fala sobre a responsabilidade pela promoção da saúde:

Deve ser compartilhada entre indivíduos, comunidade, grupos, profissionais da saúde, instituições que prestam serviços de saúde e governos. Todos devem trabalhar juntos, no sentido de criarem um sistema de saúde que contribua para a conquista de um elevado nível de saúde (OTTAWA, 1986, p. 3).

Tal definição de saúde aproxima-se do conceito ampliado de saúde proposto e aprovado em março de 1986, na $8^{\text {a }}$ Conferência Nacional de Saúde. Após a conferência, a definição de saúde passou a ser considerada não apenas como ausência de doença, mas sim como resultado de diversos fatores como a organização social, as condições gerais de alimentação, as condições de moradia, o acesso à educação, a relação com o meio ambiente, o emprego e renda, as oportunidades de lazer, a posse de terra e o acesso aos serviços de saúde (BRASIL, 1987).

"A sociedade brasileira, especialmente durante a década originada em 1980, tem adquirido a consciência de seu direito à saúde" (DALLARI, 1988, p. 57). Mesmo com nítidas melhorias no sistema de saúde e a ampliação de serviços após as conquistas da Constituição da República Federativa do Brasil, ainda assim existem lacunas, principalmente relacionadas aos modelos de atenção, a necessidade de melhoria da qualidade da assistência e da gestão dos serviços (DAGNINO, 2009).

\footnotetext{
De certo modo, as leis explicitam um consenso do movimento sanitário sobre a importância de o setor saúde atuar na definição do conteúdo da formação profissional, refletindo o interesse pela definição e ampliação das consciências individuais dos profissionais e futuros profissionais da rede pública de saúde, quanto à concretização dos princípios do SUS (LEMOS, 2010, p. 11).
}

Ao contemplar a saúde como direito de todos, o Ministério da Saúde traz a seguinte afirmação de sua relação com o desenvolvimento:

A Saúde constitui um direito social básico para as condições de cidadania da população brasileira. Um país somente pode ser denominado 'desenvolvido' se seus cidadãos forem saudáveis, o que depende tanto da organização e do funcionamento do sistema de saúde quanto das condições gerais de vida associadas ao modelo de desenvolvimento vigente (BRASIL, 2008, p. 5).

Existe um desafio na concretização dos direitos fundamentais e sociais, pois a constitucionalização destes direitos não é o bastante para a garantia de sua operacionalização. Assim, uma alternativa adotada no modelo de saúde vigente no Brasil é a descentralização das responsabilidades entre as esferas federal, estadual e municipal, deste modo buscando o planejamento das ações que priorizam as necessidades específicas de cada população (BRASIL, 2008). 
Gadelha e Costa (2007) promovem uma reflexão acerca da saúde no contexto de uma política nacional de desenvolvimento e apontam que a saúde tem sua importância reconhecida mundialmente como indutor de desenvolvimento. Os autores consideram que as delimitações políticas e institucionais não são suficientes para delimitar problemas epidemiológicos e no sistema de saúde. Ressaltam que as condições de saúde da população impactam nos problemas e na superação dos desafios rumo ao desenvolvimento desejável de determinados territórios.

Essa situação reflete a mesma encontrada por Nuske et al., (2017, p.2):

A saúde tem um papel de propulsora de desenvolvimento na sua dimensão regional com a missão pautada pelo marcante corte territorial das iniquidades socioeconômicas nacionais e assim constituindo-se como um campo de particular relevância para coesão social e econômica no território nacional.

Vários elementos devem ser contemplados ao considerar o desenvolvimento de uma região, entre eles o bem-estar populacional. Esta condição ocorrerá de forma singular em cada região, dependente de ações que favoreçam a qualidade de vida das pessoas. Sendo assim, concentram-se neste momento os argumentos contribuintes à saúde, considerando que falar sobre desenvolvimento envolve reconhecer este como um agente de mudança, que irá refletir em melhorias políticas, econômicas, culturais e humanas (OLIVEIRA, 2002).

Fazendo uso dos fatores produtivos disponíveis e por meio da utilização de seu potencial endógeno, uma sociedade é capaz de favorecer o processo de desenvolvimento regional. Deste modo, o processo de desenvolvimento endógeno se dá de forma sociocultural e econômica. As formas socioculturais acontecem mediante o bom uso dos valores e aspectos culturais. As formas econômicas são quando a sociedade se organiza e utiliza os fatores produtivos locais. Com essa combinação tem como base para o desenvolvimento regional as instituições regionais e a própria sociedade (BARQUERO, 1988).

Sobre o desenvolvimento Utria $(1969$, p. 16) afirma que "[...] se trata de um intenso e articulado processo de sequência de fatos sociais, intimamente ligados, inter-relacionados, no qual, cada um é, ao mesmo tempo efeito e causa e todos exercem ação mútua recíproca".

Para os economistas o conceito de desenvolvimento geralmente está associado aos aspectos econômicos, pois estes fatores podem ser mensuráveis e apresentar indicadores quantitativos de crescimento. Porém, Celso Furtado além de reconhecer a importância dos aspectos econômicos, ressalta o aperfeiçoamento qualitativo: "[...] o desenvolvimento não é simples questão de aumento de oferta de bens ou de acumulação de capital; possui ele um sentido, é um conjunto de respostas a um projeto de autotransformação de uma coletividade humana" (FURTADO, 1973, p. 130). Para o autor, o processo de desenvolvimento proporciona a satisfação de um crescente número de necessidades humanas, sendo a saúde uma das envolvidas.

Em conformidade com essas premissas, Gadelha e Costa (2007) defendem a relação entre saúde e desenvolvimento econômico. Os autores consideram que havendo condições adequadas de atendimento à saúde, de certa forma refletem em benefícios ao capital humano, constituindo um valor intrínseco favorável ao desenvolvimento econômico. desse

Knopp (2008, p. 13), ao falar sobre desenvolvimento regional expressa a necessidade 
[...] processo se realizar de forma mais "amigável”, sendo geográfica, social e culturalmente referenciado, e promovendo uma transformação social profunda, considerando como aspectos fundamentais a inclusão social, a cidadania e a realização das potencialidades humanas. Para tanto, reconhece-se que é essencial que sejam desenvolvidos projetos e políticas públicas interdependentes, multirrelacionais, integradas, que englobem todos os aspectos da vida de uma coletividade, ou seja, articulando e promovendo educação, cultura, saúde, esporte, qualificação urbana entre outros, para que se alcance o desenvolvimento almejado.

O desenvolvimento pode interferir em diversos aspectos das condições de vida de uma população, dentre esses aspectos a saúde deve estar incluída (CAIDEN; CARAVANTES, 1988). Estudos apontam a relação entre saúde e desenvolvimento e demonstram os impactos positivos na qualidade de vida da população, quando há condições favoráveis que envolvem fatores contemplados no conceito ampliado de saúde como moradia, lazer, segurança, saneamento, educação e acesso a serviços de saúde (PAWLOWYTSCH, 2014. RATOCHINSKI, 2015).

Conforme a Declaração de Jacarta sobre Promoção da Saúde no século XXI, a relação entre saúde e desenvolvimento aponta para os determinantes da saúde, ressaltando a necessidade de acesso à informação, o encorajamento e participação popular. "A saúde é um direito humano fundamental e essencial para o desenvolvimento social e econômico" (WHO, 1997, p. 3).

Constata-se que "[...] a saúde como qualidade de vida implica pensar em sua conexão estrutural com o desenvolvimento econômico, a equidade, a sustentabilidade ambiental e a mobilização política da sociedade" (GADELHA; COSTA, 2011, p. 7). Deste modo, a discussão sobre a saúde deve considerar as necessidades locais e estar sustentada através de políticas públicas que gerem um efeito direto sobre a população e profissionais.

\section{O PROGRAMA NACIONAL DE SEGURANÇA DO PACIENTE NO PLANALTO NORTE CATARINENSE}

O Planalto Norte Catarinense apresenta indicadores sociais, em especial indicadores de saúde, que apontam para quadros preocupantes. Por isso, vale ressaltar que para a implantação do Programa Nacional de Segurança do Paciente, diversas iniciativas estaduais contribuíram para conscientizar os profissionais e gestores de saúde quanto à importância da temática.

Albuquerque e Vandresen (2017) relatam a implantação do Programa Nacional de Segurança do Paciente na região do Planalto Norte Catarinense e descrevem as ações concretizadas desde a publicação da Portaria MS 529 de $1^{\circ}$ de abril de 2013. As seguintes ações são descritas: I Oficina Estadual sobre Segurança do Paciente, realizada em Florianópolis; em 2014, dando continuidade às discussões, teve a II Oficina Estadual sobre Segurança do Paciente; e em 2015 o Seminário de Segurança do Paciente e as Redes de Atenção à Saúde. Segundo os autores, as atividades foram desenvolvidas por meio de parcerias entre a Secretaria Estadual de Saúde de Santa Catarina, Vigilância Sanitária Estadual, instituições de ensino e demais serviços de apoio. As ações objetivaram promover uma reflexão sobre a temática e 
sensibilizar profissionais e gestores quanto à implantação do PNSP nos serviços de saúde do estado de SC.

Em maio de 2013, por iniciativa do articulador da Comissão de Integração EnsinoServiço (CIES) do Planalto Norte Catarinense, foi formado um grupo de profissionais dos serviços hospitalares para discussão das portarias. Posteriormente "[...] foram mobilizados então os hospitais da região do Planalto Norte Catarinense para a criação e implantação do Núcleo de Segurança do Paciente Regional do Planalto Norte” (ZANLUCA, 2016, p. 13).

Em estudo regional realizado, Zanluca (2016) teve acesso ao Regimento Interno do NSP do PNC no qual consta como objetivo:

Ampliar a segurança dos pacientes hospitalizados nas instituições da referida região; promover a disseminação sistemática da cultura de segurança; fortalecer o vínculo entre as instituições através de discussões e compartilhamento de experiências; atender as exigências da RDC 36/2013 (ZANLUCA, 2016, p. 14).

Com a presente iniciativa, ocorreu a aproximação dos profissionais de saúde dos hospitais do PNC, oportunizando espaços de discussão e construção, formando um elo com a Educação Permanente em Saúde.

"As reuniões de grupo vão em busca das principais dificuldades e a procura para a melhor implantação das ações e dos protocolos de segurança do paciente com o foco nos problemas de maior incidência" (ZANLUCA, 2016, p. 13). Sobre os seis protocolos básicos do Programa Nacional de Segurança do Paciente (PNSP) e sua implantação, os profissionais dos hospitais do PNC reconhecem que uma das maiores dificuldades vivenciadas é a rotatividade dos profissionais, o que impede a continuidade do processo (ZANLUCA, 2016).

Além das reuniões periódicas, o Núcleo de Segurança do Paciente do Planalto Norte Catarinense realizou o I Seminário de Segurança do Paciente em 2014, o II Seminário de Segurança do Paciente em 2015, e o III Seminário de Segurança do Paciente em 2016 (ALBUQUERQUE; VANDRESEN, 2017).

Além da implantação do Núcleo de Segurança do Paciente (NSP), os serviços de saúde precisam que este núcleo seja cadastrado na plataforma da ANVISA, para gerar indicadores nacionais e estaduais, visando o acompanhamento do cumprimento da legislação específica do Programa Nacional de Segurança do Paciente.

Em relatório disponível na plataforma da ANVISA, atualizado em 18 de janeiro de 2019, estão cadastrados em Santa Catarina 202 (duzentos e dois) Núcleos de Segurança do Paciente. Estes núcleos são em hospitais, clínicas privadas e atenção básica de saúde. Considerando os 295 municípios no estado, percebe-se que com 5 (cinco) anos de implantação do PNSP ainda falta adesão dos serviços no cumprimento das determinações.

Conforme dados obtidos no cadastro da Vigilância Sanitária, quanto à implantação do Núcleo de Segurança do Paciente no Planalto Norte Catarinense, dos 13 (treze) municípios não há cadastro de Secretarias Municipais de Saúde, os núcleos cadastrados são em Hospitais e clínicas, e os mesmos são representados no quadro a seguir (Quadro 2): 
Quadro 2 - Núcleos de Segurança do Paciente cadastrados na Anvisa

\begin{tabular}{|c|c|c|c|}
\hline Delimitação & Janeiro/2017 & Julho/2018 & Janeiro/2019 \\
\hline Estado de SC & 141 & 185 & 202 \\
\hline PNC & 08 & 12 & 13 \\
\hline
\end{tabular}

Fonte: Dados da pesquisa (2019).

Pelas informações do Quadro 2 pode-se fazer uma comparação dos últimos 03 (três) anos, é notável o avanço no cadastramento junto à ANVISA das instituições que tem os serviços implantados. Em Janeiro de 201708 (oito) NSP estavam cadastrados no PNC, destes 02 (dois) são em clínicas e 06 (seis) em hospitais. Em Julho/2018 teve um aumento para 12 (doze) NSP, sendo 04 (quatro) em clínicas e 08 (oito) em hospitais. Em Janeiro/2019 um total de 13 (treze) NSP formalmente cadastrados na ANVISA, sendo 04 (quatro) em clínicas privadas e 09 (nove) em hospitais.

Mesmo reconhecendo o aumento nos cadastros de NSP, ao considerar que a implantação do programa no Brasil foi em abril de 2013, ainda há muito a avançar para haver a efetiva conscientização sobre as ações necessárias para a segurança no cuidado ao paciente. Pois dos 14 (quatorze) hospitais que fazem parte da região do PNC, 05 (cinco) ainda não possuem NSP formalmente cadastrados em conformidade com as determinações da ANVISA.

A distribuição dos Núcleos de Segurança do Paciente cadastrados na região do PNC conforme municípios e perfil institucional de clínicas privadas e hospitais públicos são demonstrados no quadro a seguir (Quadro 3):

Quadro 3 - Núcleos de Segurança do Paciente do PNC Cadastrados na ANVISA

\begin{tabular}{|l|c|c|c|c|c|c|}
\hline \multirow{2}{*}{\multicolumn{1}{c|}{ MUNICÍPIO }} & \multicolumn{2}{c|}{ Janeiro/2017 } & \multicolumn{2}{c|}{ Julho/2018 } & \multicolumn{2}{c|}{ Janeiro/2019 } \\
\cline { 2 - 7 } & Clinica & Hospital & Clinica & Hospital & Clinica & Hospital \\
\hline Campo Alegre & & 01 & & 01 & & 01 \\
\hline Canoinhas & & 01 & & 01 & & 01 \\
\hline Mafra & 02 & 01 & 03 & 02 & 03 & 02 \\
\hline Porto União & & 01 & 01 & 01 & 01 & 01 \\
\hline Rio Negrinho & & & 01 & & 01 & 01 \\
\hline São Bento do Sul & \multicolumn{2}{|c|}{$\mathbf{0 8}$} & \multicolumn{2}{|c|}{$\mathbf{1 2}$} & & $\mathbf{1 3}$ \\
\hline TOTAL & \multicolumn{2}{|c|}{02} & & & & \\
\hline
\end{tabular}

Fonte: Dados da pesquisa (2019).

Os municípios que fazem parte da região, porém que não constam no Quadro 3, são porque nos períodos de emissão de relatório ainda não haviam realizado cadastro de NSP. Isso retrata uma realidade que necessita de maior adesão por parte dos serviços de saúde e valorização dos profissionais para as determinações do PNSP. Vale destacar que a adesão não é voluntária, mas sim determinada pelo PNSP, e sua efetivação é acompanhada pela vigilância sanitária.

Uma importante atribuição do Núcleo de Segurança do Paciente é levar ao conhecimento dos profissionais de saúde que a ocorrência de Eventos Adversos relacionados à assistência à saúde deve ser notificada ao NSP, e este deve realizar a notificação no Sistema Nacional de Vigilância Sanitária (NOTIVISA) (BRASIL, 2014), com vistas a promover a 
prática da cultura de segurança e estimular a adoção de barreiras nos sistemas de saúde para a minimização destes eventos ou de seus danos.

Apesar da vigilância constante, os profissionais de saúde precisam se sentir seguros para admitir as falhas e em seguida se manifestar a respeito realizando o registro, em formulário próprio para este fim, que busca criar uma abordagem sistêmica do ocorrido. Por isso, apesar de sua obrigatoriedade, o processo de notificação e investigação do evento adverso vem de encontro com a cultura não punitiva.

Os indicadores públicos, divulgados pela ANVISA são sigilosos, não identificam o paciente, o profissional de saúde, nem a instituição de ocorrência. No processo de notificação, a identidade do notificante é preservada, assim ao preencher o formulário não há obrigatoriedade de se identificar com o nome, pois a abordagem da investigação e condução pós-evento é generalista, buscando não o profissional diretamente envolvido no evento, mas sim todos os fatores contribuintes para o desfecho.

Os serviços cadastrados, gradativamente estão realizando as notificações de eventos adversos na plataforma da ANVISA. Em SC apenas 24 (vinte e quatro) hospitais são notificantes, dos 13 (treze) Núcleo de Segurança do Paciente do Planalto Norte Catarinense cadastrados, apenas 02 (dois) são notificantes (BRASIL, 2017).

Em estudo prévio realizado com integrantes do grupo regional de Segurança do Paciente no Planalto Norte Catarinense, 05 (cinco) hospitais responderam que realizam a notificação de eventos adversos, sendo 02 (dois) hospitais de Mafra, 01 (um) de São Bento do Sul, 01 (um) de Canoinhas e 01 (um) de Três Barras (ZANLUCA, 2016).

Há divergência de informações no estudo realizado por Zanluca (2016) e nos dados informados à ANVISA. O que se supõe é que os hospitais até fazem a notificação, porém os indicadores são acompanhados apenas internamente, e não são informados ao NOTIVISA. A situação reflete o que a Organização Mundial da Saúde aponta sobre a necessidade de se estabelecer uma cultura de segurança, pois ainda é constante o medo de punição pela ocorrência de erros assistenciais.

Os números de serviços de saúde que cumprem a determinação de notificar os eventos adversos à ANVISA precisam avançar, pois ferramentas mensuráveis como os indicadores e as investigações podem ser úteis ao avaliar as práticas de trabalho. Sem acompanhar os dados não há como reconhecer se as ações de sensibilização resultaram em mudança concreta na segurança da assistência.

Notificar a ocorrência dos eventos adversos faz parte do processo de vigilância e monitoramento em saúde, e tem como objetivo o reconhecimento por parte de cada serviço sobre os aspectos que precisam ser melhorados. Assim, identifica-se uma oportunidade de melhoria para incentivar uma cultura de segurança ao identificar, investigar, analisar e corrigir inadequações.

No cenário nacional, Santa Catarina é o sexto estado em número de hospitais que realizaram notificações de eventos adversos, com 81(oitenta e uma) instituições. É importante destacar que, no período considerado havia aproximadamente 185 (cento e oitenta e cinco) Núcleos de Segurança do Paciente cadastrados no estado, porém o que fica nítido é que nem 
todos estão com o processo de vigilância e notificações de eventos implantados ou efetivamente sendo realizado.

O gradativo aumento das notificações pode sugerir que o Programa Nacional de Segurança do Paciente vai sendo fortalecido aos poucos nos serviços de saúde, e que os profissionais estão dispostos a reconhecer os aspectos a serem corrigidos e a criar barreiras preventivas. Todos os envolvidos nos serviços de saúde devem ser sensibilizados para a detecção dos eventos adversos, que se constituem em complicações indesejadas decorrentes de assistência à saúde, pois “[...] reconhecendo-os como um instrumento de melhoria contínua para segurança do paciente, e não como um mecanismo de punição” (BRASIL, 2017, p. 86).

Em Santa Catarina, grande parte dos eventos notificados se concentra em falhas durante a assistência à saúde (2.994), úlcera por pressão (2.607), queda do paciente (1.736) e falha na identificação do paciente (1.116). As demais situações são falhas na administração de dietas (309), falha na documentação (114), falhas durante procedimentos cirúrgicos (107), falhas nas atividades administrativas (92), falhas ocorridas em laboratórios clínicos ou de patologia (78), acidentes do paciente (62), queimaduras (61), falhas na administração de oxigênio ou gases medicinais (10) e falhas no cuidado/proteção do paciente (01).

Os serviços de saúde no Planalto Norte Catarinense possuem características específicas, resultantes do contexto político, social e cultural regionais. A limitação de recursos humanos e tecnológicos, a rotatividade profissional, a carência de especialidades, a descontinuidade da assistência, entre outros problemas no sistema de saúde, são agravantes que resultam na ocorrência de eventos adversos evitáveis.

Ao considerar o conhecimento do perfil de eventos adversos no Estado de Santa Catarina, e que o Planalto Norte Catarinense é representado por dois hospitais notificantes, planejar ações que envolvam ações de educação permanente em saúde voltadas ao contexto regional podem contribuir na reflexão sobre as falhas e suas consequências, oportunizando a criação e revisão de protocolos e o estabelecimento de barreiras preventivas. $\mathrm{O}$ envolvimento do paciente é reconhecido como essencial para a qualidade e segurança assistencial. Nesse sentido, vale ressaltar que, a ANVISA criou o Módulo Cidadão que permite a notificação dos incidentes pela população, seja o próprio paciente, um familiar, amigo ou conhecido (BRASIL, 2016).

O Módulo Cidadão se torna uma ferramenta para que a população possa se tornar protagonista no processo, e não se cale diante dos eventos adversos ou situações de não conformidade relacionada à assistência recebida. Por isso, o conhecimento acerca deste instrumento deve ser divulgado, para que mais pessoas possam aderir e contribuir para que prioridades sejam estabelecidas e melhorias se concretizem de acordo com as especificidades de cada serviço.

O número de notificações por parte da população é de 217 (duzentos e dezessete) incidentes no Brasil e 10 (dez) em Santa Catarina. Pode-se considerar que talvez a população desconheça esses meios de formalização e, por isso, cada vez mais deve ser incentivada a inclusão do paciente e familiar em sugestões que contribuam para a sua própria segurança. Essa recomendação foi estabelecida pela Organização Mundial da Saúde na Aliança Mundial para a Segurança do Paciente entre 2008 e 2009 (NASCIMENTO; DRAGANOV, 2015). 
Após analisar os indicadores nacionais e estaduais do Programa Nacional de Segurança do Paciente, ainda não há como mensurar os impactos que os eventos adversos têm causado a todos os envolvidos. Por isso é imprescindível que ao reconhecer as fragilidades nos serviços de saúde, os profissionais busquem refletir sobre a segurança no cuidado prestado, assim, deve haver o questionamento dos processos de trabalho e vigilância constantes.

\section{CONSIDERAÇÕES FINAIS}

Definiu-se como objetivo geral para a pesquisa, refletir sobre a segurança do cuidado ao paciente e sua relação com o desenvolvimento regional. Ao ponderar a saúde no contexto de uma política nacional de desenvolvimento, devemos considerar que as condições de saúde de determinada população impactam positivamente ou negativamente na busca pelo desenvolvimento desejável. As ações do Programa Nacional de Segurança do Paciente e a representação destas ações sobre o desenvolvimento regional estão atreladas a determinantes históricos, políticos e sociais e estes influenciam de forma direta na atuação profissional e na assistência à saúde/doença.

A implantação das ações do Programa Nacional de Segurança do Paciente poderá ter impacto não apenas na assistência direta ao paciente, mas contribuirá no fortalecimento do controle social, protagonismo dos profissionais de saúde e usuários dos serviços e, também para uma gestão participativa.

Os espaços coletivos são ferramentas importantes para valorizar o protagonismo dos sujeitos, dessa forma, esses espaços precisam ser criados e/ou fortalecidos, para que de forma contínua possam contribuir no sentido de impulsionar uma política nacional de desenvolvimento. A participação da população para a construção de um sistema de saúde mais seguro, pode se dar por intermédio de ações que permitam o reconhecimento dos mesmos sobre o seu papel de protagonismo nas questões sociais e políticas que envolvem a sua saúde.

\section{REFERÊNCIAS}

\section{ALBUQUERQUE, C. L. N. de; VANDRESEN, F. Iniciativas acerca do Programa}

Nacional de Segurança do Paciente no Território do Contestado. Trabalho apresentado no IV Simpósio Nacional Centenário do Contestado: Tempos de muito pasto e pouco rastro, Canoinhas, 2017.

BARQUERO, A. V. Desarrollo local: una estrategia de creación de empleo. Madrid: Ed. Pirámide, 1988. 
BRASIL. Agência Nacional de Vigilância Sanitária. Acreditação e Vigilância: mais uma qualidade para a saúde. Boletim Informativo. 2003c. Disponível em:

$<$ http://www.anvisa.gov.br/divulga/public/boletim/29_03.pdf>. Acesso em: 04 abr. 2017.

. Assistência Segura: uma reflexão teórica aplicada à prática. Brasília, 2013.

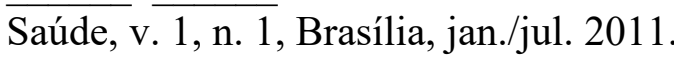

. Boletim Informativo: Segurança do Paciente e Qualidade em Serviços de

. Gestão de Riscos e Investigação de Eventos Adversos Relacionados à

Assistência à Saúde. Brasília, 2017.

Nota Técnica 01/2015 - Orientações gerais para a notificação de eventos adversos relacionados à assistência à saúde. Brasília, $2015 \mathrm{~b}$.

. Plano Integrado para a Gestão Sanitária da Segurança do Paciente em

Serviços de Saúde: Monitoramento e Investigação de Eventos Adversos e Avaliação de Práticas de Segurança do Paciente. Brasília, 2015a.

Relatório de notificações realizadas por cidadãos. Brasília, 2016.

$\overline{\text { Disponível em: }}<$ https://www20.anvisa.gov.br/segurancadopaciente/>. Acesso em: $10 \mathrm{dez}$. 2018.

Relatórios de Eventos Adversos. Brasília, 2018b. Disponível em:

$\overline{<\mathrm{https}}$ ://www20.anvisa.gov.br/segurancadopaciente/>. Acesso em: $10 \mathrm{dez} .2018$.

$2014 \mathrm{~b}$

Serviços de atenção materna e neonatal: segurança e qualidade. Brasília,

CONFERÊNCIA NACIONAL DE SAÚDE, 8. 1987. Brasília. Anais... Brasília:

Centro de Documentação do Ministério da Saúde, 1987. Disponível em:

$<$ http://www.ccs.saude.gov.br/cns/pdfs/8conferencia/8conf_nac_anais.pdf $>$. Acesso em: 16 ago. 2018.

Constituição da República Federativa do Brasil. Brasília, DF: Senado Federal: Centro Gráfico, 1988.

Lei $\mathbf{n}^{0}$ 8.080, de 19 de setembro de 1990. Lei Orgânica da Saúde. Dispõe sobre as condições para a promoção, proteção e recuperação da saúde, a organização e o funcionamento dos serviços correspondentes e dá outras providências. Brasília, 1990.

. Ministério da Saúde. A educação permanente entra na roda: pólos de educação permanente em saúde: conceitos e caminhos a percorrer. 2a ed. Brasília, 2005.

Documento de referência para o Programa Nacional de Segurança do

Paciente. Fundação Oswaldo Cruz, Brasília, 2014a.

Política de educação e desenvolvimento para o SUS: caminhos para a educação permanente em saúde: pólos de educação permanente em saúde. Brasília, 2003a.

DRd - Desenvolvimento Regional em debate (ISSNe 2237-9029) 
Política de educação e desenvolvimento para o SUS: caminhos para a educação permanente em saúde: pólos de educação permanente em saúde. Brasília, DF. $2004 b$.

Política Nacional de Educação Permanente em Saúde. Série B - Textos

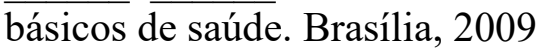

Portaria n. 198. Institui a Política Nacional de Educação Permanente em Saúde como estratégia do Sistema Único de Saúde para a formação e o desenvolvimento de trabalhadores para o setor e dá outras providencias. Brasília, DF. 2004a.

Portaria n. 1.996. Substitui a Portaria n. 198/04. Política Nacional de Educação Permanente em Saúde. Departamento de Gestão da Educação na Saúde. Secretaria de Gestão do Trabalho e da Educação na Saúde. Brasília, DF. 2007.

Programa para o Fortalecimento das Práticas de Educação Permanente em Saúde no SUS - PRO EPS SUS. Manual Técnico. Brasília, 2018a.

. Resolução do Conselho Nacional de Saúde - CNS No.335, que aprova "Política Nacional de Formação e Desenvolvimento para o SUS: Caminhos para a Educação Permanente em Saúde" e a estratégia de "Pólos ou Rodas de Educação Permanente em Saúde. Brasília, 2003b.

. Secretaria Executiva. Departamento de Apoio à Descentralização. Mais saúde: direito de todos. 2.ed. Brasília, 2008.

BAZZANELLA, S. L. Saúde, desenvolvimento humano e regional. Saúde e meio ambiente: revista interdisciplinar, v. 3, n. 2, p. 3-18, 2015.

BUENO, A. A.B.; FASSARELLA, C. S. Segurança do Paciente: uma reflexão sobre sua trajetória histórica. Revista Acadêmica Rede de Cuidados em Saúde, Universidade Unigranrio, v. 6, n. 1, p. 1-9, 2012.

CAIDEN, G.; CARAVANTES, G. T. Reconsideração do conceito de desenvolvimento. Caxias do Sul: EDUCS, 1988.

CARTA DE OTTAWA. In: CONFERÊNCIA INTERNACIONAL SOBRE PROMOÇÃO DA SAÚDE, 1. Ottawa, Canadá; 1986. Disponível em: <http://bvsms.saude.gov.br/bvs/ publicacoes/carta_ottawa.pdf>. Acesso em: 02 nov. 2017.

CECCIM, R. B.; FEUERWERKER, L. C. M. O Quadrilátero da Formação para a Área da Saúde: Ensino, Gestão, Atenção e Controle Social. Revista Saúde Coletiva, Rio de Janeiro, v. 14, n. 1, p. 41-65, 2004.

CORBELLINI, V. L. et al. Eventos adversos relacionados a medicamentos: percepção dos técnicos e auxiliares de enfermagem. Revista Brasileira de Enfermagem, v. 64, n. 2, mar./abr. 2011.

DAGNINO, R. P. Planejamento estratégico governamental. Departamento de Ciências da Administração. Florianópolis: CAPES/UAB, 2009. 
DALlaRI, S. G. O direito à saúde. Revista de Saúde Pública, São Paulo, v. 22, n. 1, p. 57 63, 1988.

DONABEDIAN, A. A. A gestão da qualidade total na perspectiva dos serviços de saúde. Rio de Janeiro: Qualitymark, 1994.

FORTUNA, C. M. et al. Educação permanente na estratégia saúde da família: repensando os grupos educativos. Revista Latino-Americana de Enfermagem., v. 21, n. 4, p. 1-9, jul./ago. 2013.

FOUCAULT, M. O nascimento do hospital. In: Microfísica do poder. Rio de Janeiro: Graal, 1979. 1994.

História da sexualidade. Tradução Pedro Tamen. Lisboa: Relógio D’Água Editores, Microfísica do poder. 16.ed. São Paulo: Graal. 2001.

. Segurança, território, população. São Paulo: Martins Fontes, 2008a. $2008 b$.

. Nascimento da biopolítica. Trad. Eduardo Brandão. São Paulo: Martins Fontes,

FREIRE, P. Extensão ou comunicação? Rio de Janeiro: Paz e Terra, 1980.

FURTADO, C. A hegemonia dos Estados Unidos e o sub-desenvolvimento da América Latina. Rio de Janeiro: Civilização Brasileira, 1973.

GADELHA, C. A. G.; COSTA, L. Integração de fronteiras: a saúde no contexto de uma política nacional de desenvolvimento. Cadernos de Saúde Pública, v. 23, supl. 2, p. S214S226, 2007.

GADELHA, C. A. G.; COSTA, L. A Saúde e territorialização na perspectiva do desenvolvimento. Ciência \& Saúde Coletiva, v. 16, n. 6, p. 3003-3016, 2011.

HENCKEMAIER, L. O imaginário da segurança do paciente na perspectiva das famílias que vivenciam o quotidiano de hospitalização. Florianópolis: UFSC, 2016. Tese (Doutorado em Enfermagem) - Programa de Pós-Graduação em Enfermagem do Centro de Ciências da Saúde, Universidade Federal de Santa Catarina, Florianópolis, 2016.

HERDEIRO, M. T. et al. Influence of pharmacists' attitudes on adverse drug reaction reporting. Drug safety, v. 29, n. 4, p. 331-340, 2006.

KALSING, R. M. K. A percepção da equipe de enfermagem frente à notificação de eventos adversos. Trabalho de Conclusão de Curso der Enfermagem. Lajeado: UNIVATES, 2012.

KNOPP, G. C. Cultura e desenvolvimento local: um estudo do Programa Bairro-Escola da cidade de Nova Iguaçu. Dissertação. Fundação Getúlio Vargas, Rio de Janeiro, 2008. 
LEENDERTSE, A. J. et al. Frequency of and Risk Factors for Preventable MedicationRelated Hospital Admissions in the Netherlands. Arch Intern Med, v. 168, p. 1890-1896, sep. 2008. Disponível em: <https://www.ncbi.nlm.nih.gov/pubmed/18809816>. Acesso em: 26 fev. 2018.

LEMOS, C. L. S. A concepção de educação da política nacional de educação permanente em saúde. Tese (Doutorado) em Educação. Universidade Federal de Goiás, Faculdade de Educação, 2010.

LIMA, H. B. et al. Políticas Públicas de Educação Profissional em Saúde no Brasil. $5^{\circ}$ Congresso Ibero-Americano em Investigação Qualitativa. Portugal, 2016.

LOEFLER, I. Why the Hippocratic ideals are dead. BMJ, v. 324, n. 7351, p. 1463, June 2002.

MANCIA, J. R.; CABRAL, L. C.; KOERICH, M. S. Educação Permanente no Contexto da Enfermagem na Saúde. Revista Brasileira de Enfermagem, v. 57, n. 5, p. 605-610, 2004.

MENDES, W. et al. Adaptação dos instrumentos de avaliação de eventos adversos para uso em hospitais brasileiros. Revista brasileira de Epidemiologia, v. 11, n. 1, p. 55-66, 2008.

MENDONÇA, F. de F. et al. Avaliação de tutores e facilitadores sobre o processo de formação de facilitadores de Educação Permanente em Saúde no município de Londrina, Paraná. Revista Ciência e Saúde Coletiva. v. 15, n. 5, p. 2593-2602, 2010.

MERHY, E. E. O desafio que a educação permanente tem em si: a pedagogia da implicação. Interface - Comunicação, Saúde, Educação, v. 9, n. 16, p. 161-177, set. 2004/fev. 2005.

NASCIMENTO, J. C.; DRAGANOV, P. B. História da qualidade em segurança do paciente. Historia da Enfermagem Revista Electronica, v. 6, n. 2, p. 299-309, 2015.

NIGHTINGALE, F. Notes on hospitals. 3. ed. London: Longman, Green, Longman, Roberts, 1863.

NUSKE, M. A. et al. A saúde e sua relação com o desenvolvimento: um olhar crítico acerca da contribuição da saúde nas múltiplas escalas do desenvolvimento regional. In:

SEMINÁRIO INTERNACIONAL SOBRE DESENVOLVIMENTO REGIONAL, 8., 2017. Santa Crus do Sul. Anais..., Santa Cruz do Sul, 13 a 15 set. 2017.

OLIVEIRA, G. B. de. Uma discussão sobre o conceito de desenvolvimento. Revista da FAE, Curitiba, v. 5, n. 2, p. 37-48, maio/ago. 2002.

PADILHA, K. G. Ocorrências iatrogênicas em Unidade de Terapia Intensiva (UTI): análise dos fatores relacionados. Revista paulista de enfermagem, v. 25, n. 1, p. 18-23, 2006.

PAESE, F. Cultura da segurança do paciente na atenção primária à saúde. Dissertação (Mestrado em Enfermagem) - Programa de Pós-Graduação em Enfermagem da UFSC, Florianópolis, 2010. 
PAWLOWYTSCH, P. W. da M. A pobreza no Planalto Norte Catarinense: representações sociais e implicações no desenvolvimento regional. Canoinhas: UnC, 2014. Dissertação (Mestrado em Desenvolvimento Regional) - Programa de Mestrado em Desenvolvimento Regional, Universidade do Contestado, Canoinhas, 2014.

RATOCHINSKI, C. M. W. Agricultura familiar: um estudo da saúde do produtor de tabaco. Canoinhas: UnC, 2015. Dissertação (Mestrado em Desenvolvimento Regional) - Programa de Mestrado em Desenvolvimento Regional, Universidade do Contestado, Canoinhas, 2015.

REBRAENSP, Rede Brasileira de Enfermagem e Segurança do Paciente. Acordo básico de cooperação da rede brasileira de enfermagem e segurança do paciente. São Paulo, 2015. Disponível em: <https://www.rebraensp.com.br/phocadownload/

Acordo\%20Basico\%20da\%20REBRAENSP\%20Versao\%202015.pdf $>$. Acesso em: 04 jun. 2017.

SANDARS, J.; ESMAIL, A. The frequency and nature of medical error in primary care: understanding the diversity across studies. Fam Pract, v. 20, p. 231-236, 2003.

SANTA CATARINA. Secretaria de Estado da Saúde. Plano Diretor de Regionalização: PDR 2008. Secretaria de Estado da Saúde. - Florianópolis, 2008.

Plano Estadual de Educação Permanente em Saúde do Estado de Santa Catarina 2010-2013. Florianópolis, 2009.

. Plano de Ação Regional de Educação Permanente em Saúde- PAREPS. Região de Saúde do Planalto Norte. 2014/2017. Florianópolis, 2014.

Plano de Ação Regional de Educação Permanente em Saúde- PAREPS. Região de Saúde do Planalto Norte. 2018/2021. Florianópolis, 2017.

Processos Avaliativos de Educação Permanente em Saúde Em Santa

Catarina: uma roda que nunca parou de girar. Florianópolis, 2018. Disponível em:

https://apsredes.org/processos-avaliativos-de-eps-em-sta-catarina-uma-roda-que-nunca-paroude-girar/ acesso em: 14 nov. 2018.

SEN, A. K. Desenvolvimento como liberdade. São Paulo: Companhia das Letras, 2000.

SHERWOOD, G.; ZOMORODI, M. A new mindset for quality and safety: the QSEN competencies redefine nurses' roles in practice. Nephrology Nursing Journal, v. 41, n. 1, p. 15-22, 2014.

SILVA, S. C. Ocorrências iatrogênicas em unidades de terapia intensiva: impacto na gravidade do paciente e na carga de trabalho de enfermagem. Tese (Doutorado em Enfermagem) - Universidade de São Paulo, Escola de Enfermagem, 2003.

SILVA, A. E. B. C. Segurança do paciente: desafios para a prática e a investigação em Enfermagem. Revista Eletrônica de Enfermagem, v. 12, n. 3, Goiânia, 2012. 
SLAWOMIRSKI, L.; AURAAEN, A.; KLAZINGA, N. The economics of patient safety: Strengthening a value-base approach to reducing patient harm at national level, OECD, mar. 2017. Disponível em: $<$ https://www.oecd-ilibrary.org/social-issues-migration-health/theeconomics-of-patientsafety_5a9858cd-en>. Acesso em: 06 out. 2017.

TONDO, J. C. A. Clima de segurança: percepção dos profissionais de enfermagem em um hospital de ensino. Dissertação (Mestrado em Ciências da Saúde) - Programa de PósGraduação em Enfermagem da Faculdade de Enfermagem na Universidade Estadual de Campinas, Campinas, 2015.

UTRIA, R. Desarollo nacional, participacion popular y desarollo de la comunidad en la America Latina. México: CREPAL, 1969.

WACHTER, R. M. Compreendendo a segurança do paciente. Porto Alegre: Artmed, 2010.

WHO (World Health Organization). A Declaração de Jacarta sobre Promoção da Saúde no Século XXI. Adoptado na Quarta Conferência Internacional sobre Promoção da Saúde. Jacarta, República de Indonésia, 21-25 jul. 1997.

Estrutura conceitual da classificação internacional sobre segurança do doente. Relatório Técnico Final. Lisboa, Portugal, 2011.

Guia curricular de segurança do paciente da Organização Mundial da Saúde: edição multiprofissional. Tradução: Pontifícia Universidade Católica do Rio de Janeiro- PUCRio, Rio de Janeiro: Autografia, 2016.

10 facts on patient safety. March, 2018. Disponível em: $<$ http://www.who.int/ features/factfiles/patient_safety/en/>. Acesso em: 10 maio 2018.

ZANLUCA, C. H. Atuação dos profissionais de saúde frente ao Núcleo de Segurança do Paciente nas instituições do Planalto Norte Catarinense. Trabalho de Conclusão de Curso (Graduação de Enfermagem) - Universidade do Contestado, Mafra-SC, 2016.

Artigo recebido em: 16/04/2019

Artigo aprovado em: 01/08/2019

Artigo publicado em: 02/08/2019 